\begin{tabular}{|c|c|c|c|c|c|c|}
\hline \multirow{4}{*}{ Impact Factor: } & ISRA (India) & $=3.117$ & SIS (USA) & $=0.912$ & ICV (Poland) & $=6.630$ \\
\hline & ISI (Dubai, UAI & $=0.829$ & РИНЦ (Russia) & $=0.156$ & PIF (India) & $=1.940$ \\
\hline & GIF (Australia) & $=0.564$ & ESJI (KZ) & $=5.015$ & IBI (India) & $=4.260$ \\
\hline & JIF & $=1.500$ & SJIF (Morocco) & $=5.667$ & & \\
\hline
\end{tabular}

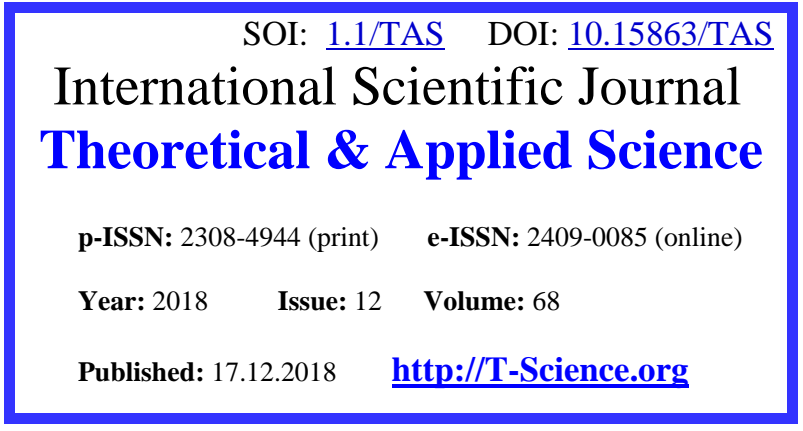

QR - Issue

QR - Article

SECTION 32. Jurisprudence.
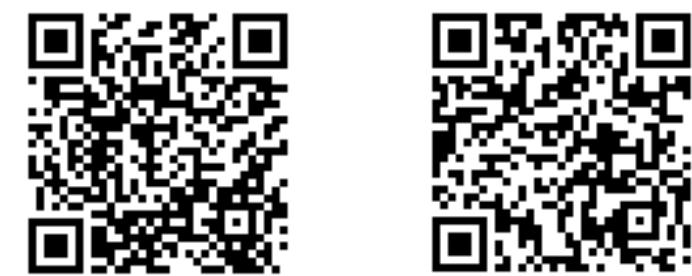

Bakitbek Eshimbekovich Kapalov Adjunct of Police Academy in Bishkek Lieutenant colonel of militia

\title{
CONCEPT AND CRIMINALISTIC SPECIFICITY OF THE ALGORITHM FOR ESTABLISHING PERSONALITY IN MASTERS OF CASE
}

\author{
Abstract: In this article, the author made an attempt to consider the concept and forensic nature of the \\ algorithm for identifying the person who committed the murder. \\ Key words: murder; algorithm; forensic characterization; the identity of the killer. \\ Language: Russian \\ Citation: Kapalov, B. E. (2018). Concept and criminalistic specificity of the algorithm for establishing \\ personality in masters of case. ISJ Theoretical \& Applied Science, 12 (68), 74-78. \\ Soi: http://s-o-i.org/1.1/TAS-12-68-15 Doi: crossef https://dx.doi.org/10.15863/TAS.2018.12.68.15

\section{ПОНЯТИЕ И КРИМИНАЛИСТИЧЕСКОЕ СПЕЦИФИКА АЛГОРИТМА УСТАНОВЛЕНИЯ ЛИЧНОСТИ ПО ДЕЛАМ ОБ УБИЙСТВАХ}

Аннотация: $B$ данной статье автором сделана попьткка рассмотреть понятие и криминалистическую сущность алгоритма установления личности, совершившего убийство.

Ключевые слова: убийство; алгоритм; криминалистическая характеристика; личность убийцыы.

Актуальность.

Причина столь бурного роста показателей насильственного преступления в сегодняшнее время очень многообразен. Их необходимо искать в нестабильных экономических социальных ситуациях, упадках общей культуры. Можно искать их и в политических сферах. Нравственные опустошения общества также оказывают свое влияния на ситуацию с преступлениями. В обществе набирают силу тенденции неуважения к праву, законам, попираниям прав личности, процветает безнравственность, теряется моральная ценность и установка.

К фактору, способствующей совершению особо тяжкого преступления, в том числе убийства мы можем отнести следующие: ненадлежащие воспитания и недостаточное внимания родителей, близкого родственника, школ, как организаций призванных не только давать образование, но принимать участие в становлениях подрастающих поколений, с формированием правовой культуры и сознания человека, без которых, будучи в зрелом возрасте, люди становятся маргинальными личностями, без ценностного ориентира и морально-нравственного качества.

Немаловажным является фактор алкогольной взаимности и наркотизм, безработица и факт отсутствия перспективы в будущем, сильные социальные расслоения в обществе, высокие степени миграции особенно в молодой среде в возрасте от 18 - 24 лет.

Согласно официльной статистике Национального статистического комитета Кыргызской Республики, больше всего трудоспособного населения покинуло Баткенскую область (более 350 тысяч человек), Джалалабадскую область оставили около 240 тыс. чел., далее следует Ошская область и Чуйская. Трудовые мигранты в поисках работы уезжают в Российскую Федерацию (более 80\%), Казахстан (10\%) и другие страны (например, Южная Корея, США, Европа) [1]. 


\begin{tabular}{|c|c|c|c|c|c|c|}
\hline \multirow{4}{*}{ Impact Factor: } & ISRA (India) & $=3.117$ & SIS (USA) & $=0.912$ & ICV (Poland) & $=6.630$ \\
\hline & ISI (Dubai, UAE & $=0.829$ & РИНЦ (Russia) & $=0.156$ & PIF (India) & $=1.940$ \\
\hline & GIF (Australia) & $=0.564$ & ESJI (KZ) & $=\mathbf{5 . 0 1 5}$ & IBI (India) & $=4.260$ \\
\hline & JIF & $=1.500$ & SJIF (Morocco) & $=5.667$ & & \\
\hline
\end{tabular}

Табл. № 1. Динамика совершенных убийств в КР

\begin{tabular}{|c|c|c|}
\hline № & Годы & Всего зарегистрировано убийств \\
\hline 1. & 1998 & 460 \\
\hline 2. & 1999 & 318 \\
\hline 3. & 2000 & 394 \\
\hline 4. & 2001 & 366 \\
\hline 5. & 2002 & 352 \\
\hline 6. & 2003 & 320 \\
\hline 7. & 2004 & 299 \\
\hline 8. & 2005 & 329 \\
\hline 9. & 2006 & 299 \\
\hline 10. & 2007 & 332 \\
\hline 11. & 2008 & 322 \\
\hline 12. & 2009 & 315 \\
\hline 13. & 2010 & 315 \\
\hline 14. & 2011 & 376 \\
\hline 15. & 2012 & 293 \\
\hline 16. & 2013 & 277 \\
\hline 17. & 2014 & 262 \\
\hline 18. & 20159 мес. & 175 \\
\hline \multicolumn{2}{|c|}{ Итого: } & $\mathbf{5 8 0 4}$ \\
\hline \multicolumn{2}{|c|}{} \\
\hline
\end{tabular}

Вышеуказанный фактор проявляется, как правило, в крупных городах, где совершаются большая часть преступления, в том числе преступления против жизни и здоровья человека.

Подчеркивая сложности раскрытия данных категорий преступлений, проблемная составляющая ситуации выступают неизвестными искомыми в качестве личности преступника. При отсутствии явного следа преступлений или очевидца, указывающего на причастность конкретных лиц к совершенным убийствам, установления личности преступников представляют большую сложность и являются первостепенными задачами неотложного и первоначального этапа следствия. Отсутствие времени и данных в таких случаях непосредственно зависит с искомым доказательством, играющим ориентирующи, оперативные или доказательственные значения.

На последующих этапах расследования стоят задачи доказывания причастности установленных лиц к совершенным преступлениям. Данные задачи наиболее эффективно решаются после исчерпывающих мер, принятых на первоначальных этапах. Например, орган следствия и дознания может иметь материальное доказательство биологического происхождения (отпечаток следов рук, след ДНК предполагаемых преступников), но не может установить лиц, являющихся носителями этих следов. Является очевидными, что в этих случаях задача доказывание будет решена сразу же после установления личности преступников, потому что результаты сравнительных исследований прямо покажут на причастность или непричастность лиц к совершениям преступлений. Причем наиболее сложная следственная ситуация как раз и характеризуется отсутствием прямого доказательства причастности лиц к совершенным преступлениям, ввиду чего приобретается особым значением системы косвенного доказательства.

В связи с этим продолжает быть актуальной разработка наиболее эффективных средств расследования и раскрытия убийств, которые содержали бы конкретные рекомендации по разрешению проблемных следственных ситуаций, складывающихся по делам этой категории. Гибкая, ситуативно обусловленная последовательность таких рекомендаций составляет суть криминалистических алгоритмов и программ расследования. Между тем ни на теоретическом, ни на практическом уровне понятие, структура, вопросы разработки и использования криминалистических алгоритмов последовательности их применения (программ расследования) при установлении лица, совершившего убийство, должного освещения не получили.

Вопросами алгоритмизации и программирования раскрытия и расследования преступлений занимались российские ученые таки так Л. Г. Видонов, В. К. Гавло, Г. А. Густов, В. Ф. Робозеров. Так, Г. А. Густов [2] и Л. Г. Видонов [3] разрабатывали криминалистические программы расследования и раскрытия убийств. В. Ф. Робозеров [4] - общие программы установления лиц, совершивших преступления. Их труды не утратили своей актуальности и сегодня, но полученные ими результаты безусловно требуют дальнейшего научного развития.

Теоретические глубоко криминалистические алгоритмы в целом осмыслены в докторской 


\begin{tabular}{|c|c|c|c|c|c|c|}
\hline \multirow{4}{*}{ Impact Factor: } & ISRA (India) & $=3.117$ & SIS (USA) & $=0.912$ & ICV (Poland) & $=6.630$ \\
\hline & ISI (Dubai, UAE & $=0.829$ & РИНЦ (Russia) & $=0.156$ & PIF (India) & $=1.940$ \\
\hline & GIF (Australia) & $=0.564$ & ESJI (KZ) & $=5.015$ & IBI (India) & $=4.260$ \\
\hline & JIF & $=1.500$ & SJIF (Morocco) & $=5.667$ & & \\
\hline
\end{tabular}

диссертации А. С. Шаталова [5]. Однако криминалистические алгоритмы установления лица, совершившего преступление, до сих пор до конца не разработаны. В значительной степени такая ситуация возникла из-за отсутствия понимания того, какие операции должны включаться в криминалистические алгоритмы установления лица, совершившего убийство, каково реальное соотношение криминалистических алгоритмов и программ, какие еще, помимо алгоритмов, элементы должна содержать программа установления личности преступника. Не исследован в литературе и вопрос о том, в чем именно выражается эффект работы системы, несводимый к результату реализации ее элементов (эффект синергии).

Само понятие «криминалистический алгоритм» является межотраслевым, оно возникло на стыке математики и криминалистики, но проблемы использования математических представлений, в том числе основанных на теориях множеств и алгоритмов, в алгоритмизации и программировании установления лица, совершившего убийство, практически не изучались. Исключение здесь в какой-то мере составляют работы В. Ю. Толстолуцкой и его учеников $[6$, с. 42-54.].

Криминалистические алгоритмы и программы установления лица, совершившего убийство, - это инструмент управления сложными социальными процессами, во-первых, происходящими в ходе раскрытия и расследования преступления (процессы управления и самоуправления расследованием), во-вторых, связанными с деятельностью преступника в контексте его взаимоотношений (связи) с жертвой (процесс установления личности преступника). Вместе с тем соответствующие понятийные аппараты и инструмент теории социальной сети к алгоритмизациям и программированиям раскрытия и расследования убийства ранее не привлекался и не использовался.

В частности, не осмысленным и не сформированным является понятие связи между жертвами и преступниками, не созданы практически значимые для расследования и раскрытия убийства классификация данной связи, не исследованы влияния на раскрытия и расследования убийства факторов социальной сети, эго-сети, центральности и силы связей, социального статуса жертв.

Вместе с тем, хотя ученые-криминалисты много лет утверждают о важности создания электронных баз данных на основах криминалистической характеристик убийства, в том числе для разработок криминалистического алгоритма установления личности убийы, практического воплощения эти идеи, за исключением программного обеспечение
«Форвер», не получила. При этом рекомендация по поиску преступников, то есть алгоритмов действия, в результате которого отдельное лицо «попадает» в круг подозреваемого, на основе этих программ не разработана, но именно такая рекомендация требуется практическому работнику для разрешения проблемной следственной ситуации.

Программы - это методы планирования и средства реализации плановой задачи [7, с. 4344].

Программы - это совокупность мероприятий, конкретизированные по сроку и направленные на осуществление конкретно определенной цели [8, с. 76]. Под программой понимается весь комплекс работы, независимо от его характера и назначений. Речь идет о разработке определенной системы. Следует сразу отметить, что эти распространенные определения фиксируют часть содержания программ - их праксеологические составляющие, при этом оставляется без внимания другие немаловажные ее части - ресурсные. В этом случае, значимым является обстоятельства определяющие программу в качестве инструмента управления интеграциями различного вида деятельности.

Интеграции между различным видом деятельности могут осуществляться согласно, как с внутриотраслевыми, так и межотраслевыми принципами. Интеграция выступает уровнем сотрудничеств, существующих между частями организаций и обеспечивающих достижения его целей в рамках требования, предъявляемого внешнему окружению [9, с. 122].

Интегрирования различного вида деятельности в комплекс всегда производятся с учетом конкретной цели. В связи с этим критериями для включения тем или иным отраслям в этот комплекс будут степени участия данных отраслей в реализации поставленных целей $[10$, с. 7]. Следует отметить, что не каждые виды деятельности требуют организационных включений в комплексы. Решающий смысл имеют интеграции на системных основах, при которых вид деятельности и ресурс объединяется и направляюеся на достижения единых целей, в связи, с чем устраняется имевшийся отраслевое и другое несогласование.

Исследователи утверждают, что перманентные цели представляют собой бесконечные ряды последовательно реализуемой цели. Для отдельной конечной цели разрабатывается конкретная программа, в процессах выполнения которой поставленная цель реализуется $[11$, с. 6$]$.

Цели - это будущие желаемые состояния объектов управления или их отдельных параметров, которые в процессах управления позволяют разрешить поставленные проблемы [12, с. 156]. Цели всегда выступают как единство 


\begin{tabular}{|c|c|c|c|c|c|c|}
\hline \multirow{4}{*}{ Impact Factor: } & ISRA (India) & $=3.117$ & SIS (USA) & $=0.912$ & ICV (Poland) & $=6.630$ \\
\hline & ISI (Dubai, UAE & $=0.829$ & РИНЦ (Russia) & $=0.156$ & PIF (India) & $=1.940$ \\
\hline & GIF (Australia) & $=0.564$ & ESJI (KZ) & $=\mathbf{5 . 0 1 5}$ & IBI (India) & $=4.260$ \\
\hline & JIF & $=1.500$ & SJIF (Morocco) & $=5.667$ & & \\
\hline
\end{tabular}

мотивов, средства и результаты. Под мотивами, как известно, понимаются стремления удовлетворить те или иные потребности. Для обретения определенностей мотивы должны быть подкреплены наличием средства, использование которых могут привести к желаемым результатам. Таким образом, цели формулируются при соединении мотивов со средством (ресурсом, условием, возможностью). Здесь и решаются вопросы о способах удовлетворения потребностей [13, с. 109].

Цели представляют собой заранее запланированные результаты, которые должны быть достигнуты с помощью какого-то действия и средства. Социальные подсистемы ориентируются на многокомпонентную цель, что потребуется при разработках плана и программы применять процедуры ранжирования целей. Любые цели при этом определяются через их качества, которая в свою очередь сравнивается относительно друг друга по ее важности. Вместе с тем в процессе формирования цели комплексных программ необходимо четкые разграничения функциональной цели, целианалога и цели развития.

Л.А. Бургановой характеризуется целеполагание в качестве сложного процесса, включающего не только образования цели, но и их проверки, корректировки, согласования, прогнозирования. Как полагают ученые, завершающим звеном целеполагания выступают программирования деятельности по достижению сформулированной цели [14, с. 63]. Организаторские функции начинаются сразу же после того, как будут установлваться цели. С их помощью создаются логические схемы комбинирования ресурса, достижение последовательности и согласованности действия всех звеньев [15, с. 9].

Программирование является результатом процесса разработки программ с определением последовательности действий и целевых предназначений, выбора вариационных (альтернативных) процессов развития для достижения запрограммированных результатов.
Программирования могут охватывать все сферы и области деятельности органа, учреждения или одну из них [16, с. 805].

Если анализировать с экономической стороны Р.А. Кочкаров полагает, что программирование является разработкой программы социально-экономического развития - комплекса целевого ориентира социальноэкономического развития и планируемых государством эффективных путей и средств достижения указанных ориентиров [17, с.13].

\section{Вывод}

Основное достоинство программно-целевого подхода в расследовании заключается в том, что на его основе можно более полно объединять и использовать все имеющиеся в наличии средства и ресурсы для решения конкретных задач. При правильном применении программно-целевой подход обеспечивает большую гибкость, динамичность и адаптивность системы управления. Это перспективный подход в управлении, позволяющий реализовать в самый короткий срок большие возможности $[18$, с. 8$]$.

Значимость изучения информации связанной с личностью преступника образует то, что общественно-опасное деяние как волеизъявление конкретного индивида в большей степени первоначально от его сущности и особенностей. В связи с чем, говоря абстрактно, само по себе преступление и преступник, совершающий его, являются теми клетками образующими организм преступности, исследовать и познавать которые способны постоянно обновлять криминалистическую ткань будущей платформы по организации и осуществлению предупреждения общественноопасных деяний.

Имеющиеся проблемы объективно не позволяют разработать криминалистические алгоритмы и программы установления личности преступника по делам об убийствах, проверить их эффективность на практике, что еще раз подтверждает актуальность назревшей проблемы и ее решения.

\section{References:}

1. (2018). Otchet Natsionalnogo statisticheskogo komiteta Kyirgyizskoy Respubliki za 2018 g.

2. Gustov, G. A. (1993). Programmno-tselevoy metod organizatsii raskryitiya ubiystv. SPb..

3. Vidonov, L. G. (2003). Tipovyie sledstvennyie situatsii pervonachalnogo etapa sledstviya po delam ob ubiystvah. Kriminalisticheskie elementyi vzaimosvyazi mezhdu elementami sostava prestupleniy dannogo vida i metodika vyidvizheniya versiy o litsah, sovershivshih ubiystva bez ochevidtsev, na osnove ukazannyih vzaimosvyazey. N. Novgorod. 


\begin{tabular}{|c|c|c|c|c|c|c|}
\hline \multirow{4}{*}{ Impact Factor: } & ISRA (India) & $=3.117$ & SIS (USA) & $=0.912$ & ICV (Poland) & $=6.630$ \\
\hline & ISI (Dubai, UAE & $=0.829$ & РИНЦ (Russia) & $=0.156$ & PIF (India) & $=1.940$ \\
\hline & GIF (Australia) & $=0.564$ & ESJI (KZ) & $=\mathbf{5 . 0 1 5}$ & IBI (India) & $=4.260$ \\
\hline & JIF & $=1.500$ & SJIF (Morocco) & $=5.667$ & & \\
\hline
\end{tabular}

4. Robozerov, V. F. (1991). Ustanovlenie lits, sovershivshih prestupleniya $v$ usloviyah neochevidnosti. Nauchno-metod. rekomendatsii. L..

5. Shatalov, A. S. (2000). Problemyi algoritmizatsii rassledovaniya prestupleniy. dis. ... d-ra nauk. M..

6. Tolstolutskiy, V. Y. (2009). Teoriya mnozhestv kak osnova formirovaniya ponyatiya «kriminalisticheskaya harakteristika prestupleniy». Innovatsii v gosudarstve i prave Rossii: materialyi Mezhdunar. nauch.-prakt. konfer. N. Novgorod.

7. Stefanov, N., Simeonova, K., Kostov, K., \& Kachaunov, S. (1975). Programmno-tselevoy podhod v upravlenii: teoriya i praktika. (pp.4344). M..

8. Salnikova, V. P. (2002). Osnovyi upravleniya v organah vnutrennih del. (p.76). M.: IMTs GUK MVD Rossii.

9. Burganova, L. A. (2009). Teoriya upravleniya: Ucheb. posobie. (p.122). M.: INFRA-M.

10. Lemeshev, M. Y., \& Panchenko, A. I. (1972). Programmnyiy podhod $v$ upravlenii ekonomikoy. «Programmnyiy podhod v planirovanii i upravlenii narodnyim hozyaystvom». (p.7). Novosibirsk.

11. Lemeshev, M. Y., \& Panchenko, A. I. Ukaz. soch., p. 6.

12. (1997). Nauka upravleniya rassmatrivaet tri vida tseley - «tseli-zadaniya», «tseliorientatsii» $\mathrm{i}$ «tseli sobstvenno sistemyi». Sm: Yaskov E.F. Slovar - spravochnik. (p.156). M.: Akad. uprav. MVD. Rossii.

13. (1990). Teoriya upravleniya $v$ sfere pravoohranitelnoy deyatelnosti. Uchebnik. In: prof. V.D. Malkova (Eds.). (p.109). M..

14. Milner, B. Z. (1980). Organizatsiya programmno-tselevogo upravleniya. (p.9). M..

15. Azriliyana, A. N. (2010). Yuridicheskiy slovar. - 2-e izd. (p.805). M..

16. Kochkarov, R. A. (2007). Tselevyie programmyi: instrumentalnaya podderzhka. (p.13). M..

17. Kadyintsev, A. N., Groshev, S. B., \& Dankov, G. L. (2009). Planirovanie kompleksnyih operatsiy $v$ gorraylinorganah vnutrennih del. (p.8). Akademiya upravleniya MVD Rossii. 